\title{
III. On a diffusion photometer
}

\author{
J. Joly M.A.B.E.
}

To cite this article: J. Joly M.A.B.E. (1888) III. On a diffusion photometer, Philosophical Magazine Series 5, 26:158, 26-28, DOI: 10.1080/14786448808628231

To link to this article: http://dx.doi.org/10.1080/14786448808628231

曲 Published online: 29 Apr 2009.

Submit your article to this journal 주다

LII Article views: 1

Q View related articles $₫$ 
therefore, desirable to ascertain if this sudden loss of permanent molecular strain would, like permanent magnetization, take place at a lower temperature than the loss of temporary susceptibility. The iron wire in the last experiment was, therefore, permanently twisted through twenty revolutions and then released from torsional stress. When, on heating, a certain temperature had been reached there was a sudden untwisting of the wire, followed after an interval of several seconds by the usual deflection of the Thomson's galvanometer, which showed that the temporary magnetic susceptibility was beginning to disappear. This experiment was repeated at least six times with different pieces of the same kind of wire, and, invariably, with the same result-the permanent torsion, like the permanent magnetism, began to disappear suddenly at a temperature considerably below the temperature at which the temporary magnetic susceptibility began to disappear.

The contrary, however, was the case with a specimen of annealed nickel wire $*$ of the same length as the iron but of rather less diameter. When this wire had received a few turns of permanent torsion $\dagger$, and was afterwards heated, the loss of temporary magnetic susceptibility occurred at a much lower temperature than the rapid loss of permanent torsion; whilst Berson has shown that the permanent magnetization of nickel resembles the permanent magnetization of iron in disappearing before the temporary susceptibility.

This experiment, therefore, shows that the temperature at which permanent magnetism begins to suddenly disappear is not the temperature at which permanent torsion begins to suddenly disappear.

III. On a Diffusion Photometer. By J. JoLx, M.A.B.E.

A PECULIAR appearance presented by a translucent A substance, when rendered discontinuous by a crack or break, is probably a matter of common observation. When such an object-it may be the familiar one of a cracked paraffin candle-is placed in an unequally illuminated field, the presence of the discontinuity shows out, in general, boldly, as a plane of separation between a bright and a dark portion of the substance. The light, in fact, diffused through the substance, passes only in a feeble degree across the crack, so that that part of the body near the source of light appears

* Containing nearly 98 per cent. of nickel

+ Only two or three turns can be given before the wire breaks.

f Communicated by the Author. 
filled with diffused light, that part furthest removed dark and obscured. The crack may be very minute, the effect is the same. Only when the edge of the crack is so turned that the source of light shines equally on either side of it, or if two sources of light of similar colour illuminate separately and with equal intensities the material at either side of the crack, does the discontinuous appearance vanish. On this effect the photometer to be described is based.

If, in fact, two parallelepipeds of paraffin be cut, of equal dimensions, and planed smooth so that they can be laid accurately together on similar faces, it will be found that a very sensitive apparatus is obtained, so that an appearance of homogeneity is only secured by nice adjustment to a plane of equal illumination. To compare two sources of light it is sufficient to place the compound parallelepiped with its plane of discontinuity at right angles to the line joining the sources of light and cut by this line. Then, shifting the parallelepiped between the lights, and regarding the fine line of division on its surface, to find the point at which this line is no longer, or only with difficulty, descernible. The distances are now measured in the usual way, and the relative intensities of the light reckoned as inversely as the squares of their distances from the plane of juncture of the parallelepiped.

In the case, however, of lights of dissimilar colour, the appearance of the photometer is no longer uniform, but that of two softly glowing substances having different shades of colour. The difficulty now of judging when equilibrium is obtained is one which must arise with all photometers which are true to colour. So far, however, as my experience goes, comparing the gas-flame with the candle, the comparison of intensity is not possessed of any uncertainty, the line showing with a minimum of distinctness when the brightness at each side is the same, and the position of equilibrium being reformed with great accuracy on repeated observation. In extreme cases tinted glasses interposed in front of the flame might be used.

The explanation of the sensitiveness of this photometer is not far to seek. The surfaces being compared are in juxtaposition and simultaneously in the field of vision. If, now, we concentrate all our attention close to the line of junction, the least disturbance in the equality of the illumination will be most favourably displayed to the perception. The light entering the eye, too, is soft and perfectly uniform over the surfaces regarded. Photometers in which a kind of visual memory has to be exerted in the comparison of two images removed some 8 or 10 centimetres from one another do not possess the same sensibility. There is, also, a notable absence 
of the fatigue attending the use of apparatus which constrain us to shift our attention from one image to another.

Recently I have changed the nature of the material to the more durable one of glass, of very similar translucency. It may be said that the nearer the glass approaches the uniform soft translucency of paraffin the better it is for the purpose. The durability secured in the use of this material and the accuracy of surface it permits in grinding and polishing are great advantages. I have also heightened the effect of the plane of separation by interposing between the parallelepipeds a film of silver leaf. This is caused to adhere by means of canada balsam, by which too they are finally cemented together. Thus prepared, their behaviour to light is very striking. In a plane of luminous equilibrium they appear as a single body lit up internally and emitting a soft light. The least flicker in one of the sources of light destroys the illusion of uniformity, and a screen interposed at one side seemingly reduces the parallelepiped to half its size.

The dimensions I find most suitable are $20 \times 50 \times 11 \mathrm{~mm}$. for ench parallelepiped. They are laid together on two of the larger faces, the parallel external faces being ground smooth, but left unpolished. The surface under observation during experiment is ground smooth and polished after the joining of the parallelepipeds. The most important points to be attended to in their construction are fineness of divisional line and uniformity in thickness. Should there be any difference in the translucency of the parallelepipeds a check observation might be made by turning over the photometer so that the halves change places relatively to the lights, taking a mean of the results. This has not been necessary with such prisms as have come under my notice.

In judging of the final position of equilibrium I am accustomed to magnify the line with a lens, but I find many observers prefer the absence of the lens. To shelter the photometer from disturbing effects of reflexions, \&c., I use a blackened box, somewhat similar in form to that used with the Bunsen photometer, but smaller in size. The usual precantion of protecting the eyes of the observer from the direct rays of the lights shonld, of course, be observed.

The effect upon which this photometer is based will be extensively observed in natural objects, as translucent minerals, where any discontinuity of substance, as a cleavage crack, occurs.

A note on the above appeared in the Proc. Roy. Dublin Soc. (vol. iv. p. 345, Dec. 1884), and the photometer was exhibited before the Berlin Physical Society by Dr. König ('Nature,' xxxiv. p. 48). 